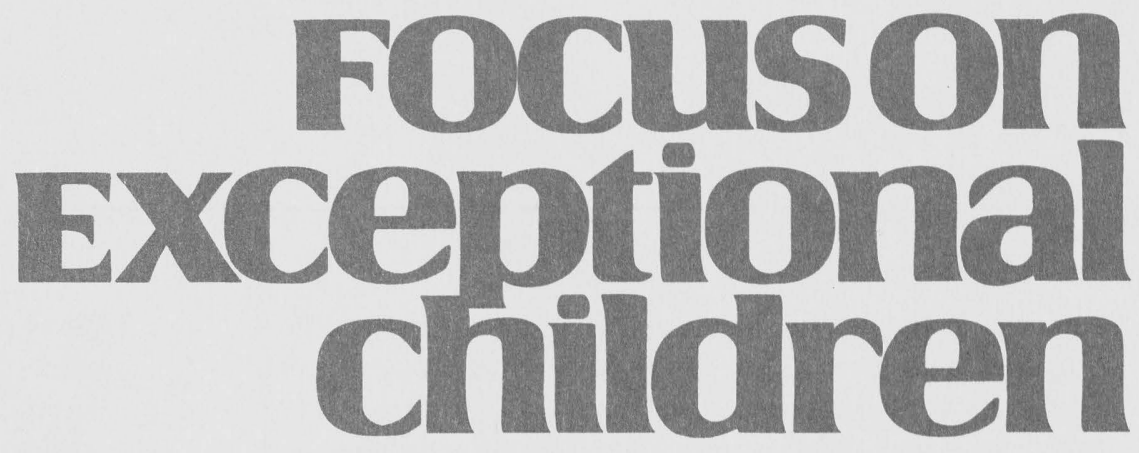

\title{
Peacemakers: Teaching Students to Resolve Their Own and Schoolmates' Conflicts
}

\author{
David W. Johnson and Roger T. Johnson
}

\begin{abstract}
"Joshua was chasing Octavia. He pushed her down and she kicked him."
"Jane was going to beat up Joan after school. They were spitting in each other's face and calling each other names."
\end{abstract}

"Tom shoved Cameron up against the lockers and threatened him. Cameron said he's going to bring a knife to school tomorrow to get even."

Schools are filled with conflicts. Considerable instructional, administrative, and learning efforts are lost because students and faculty often manage their conflicts poorly. The frequency and severity of conflicts seem to be increasing, and for the first time, the category "fighting, violence, and gangs" is tied with "lack of discipline" for the number-one problem confronting local public schools (Elam, Rose, \& Gallup, 1994). Conflicts will not go away. Students are clearly fascinated by and drawn to conflicts. They like to start them, watch them, hear about them, and discuss them. To make schools orderly and peaceful places in which high quality education can take place, conflicts must be managed constructively without physical or verbal violence. To do so, students must be taught to be peacemakers.

\section{HOW CONFLICTS CAN BE OF VALUE}

A number of points can help clarify the value of conflicts. First, conflicts are inevitable. You might as well try to stop the earth from turning on its axis as to try to eliminate conflicts from your life. No matter what you do, conflicts arise. Second, conflicts are desirable if they are managed constructively. Conflicts occur whenever people have goals they care about and are involved in relationships they value. The absence of conflict often signals a dysfunctional situation wherein neither the goals nor the relationship is valued. Conflict often signals a commitment to the goals and the relationship. This commitment fuels an engagement in conflict that can lead to either constructive or destructive outcomes. On the destructive side, conflicts can (a) create anger, hostility, lasting animosity, and even violence, (b) result in pain and sadness, and (c) end in divorce, lawsuits, and war. There is nothing pretty about a conflict gone

David W. Johnson is a professor of Educational Psychology and Roger T. Johnson is a professor of Curriculum and Instruction. They are both affiliated with the University of Minnesota College of Education and Human Development. 
wrong. On the positive side, conflicts are constructive when (a) all disputants are satisfied with the outcome (the agreement maximizes joint benefits and allows all participants to achieve their goals and, therefore, everyone goes away satisfied and pleased), (b) the relationship between the disputants is strengthened and improved (disputants are better able to work together and have more respect, trust, and liking for each other), and (c) disputants are able to resolve future conflicts constructively.

Besides these direct outcomes, conflicts have value in a number of other ways. Conflicts:

1. Focus attention on problems that have to be solved. Conflicts energize and motivate us to solve our problems.

2. Clarify who you are and what your values are. Through conflicts, your identity is developed.

3. Clarify how you need to change. Conflicts clarify and highlight patterns of behavior that are dysfunctional.

4. Help you understand who the other person is and what his or her values are. Conflicts clarify the identity of your friends and acquaintances.

\section{FOCuson Exceptional children}

FOCUS ON EXCEPTIONAL CHILDREN (USPS 203-360) is published monthly except June, July, and August as a service to teachers, special educators, curriculum specialists, administrators, and those concerned with the special education of exceptional children. This publication is annotated and indexed by the ERIC Clearinghouse on Handicapped and Gifted Children for publication in the monthly Current Index to Journals in Education (CIJE) and the quarterly index, Exceptional Children Education Resources (ECER). The full text of Focus on Exceptional Children is also available in the electronic versions of the Education Index. It is also available in microfilm from Xerox University Microfilms, Ann Arbor, MI. Subscription rates: Individual, $\$ 30$ per year; institutions, $\$ 40$ per year. Copyright $\odot 1996$, Love Publishing Company. All rights reserved. Reproduction in whole or part without written permission is prohibited. Printed in the United States of America. Second class postage is paid at Denver, Colorado. POSTMASTER: Send address changes to:

$$
\begin{gathered}
\text { Love Publishing Company } \\
\text { Executive and Editorial Office } \\
\text { P.O. Box } 22353 \\
\text { Denver, Colorado } 80222 \\
\text { Telephone (303) } 757-2579
\end{gathered}
$$

Edward L. Meyen

University of Kansas

Richard J. Whelan

University of Kansas Medical Center
5. Strengthen relationships by increasing your confidence that the two of you can resolve your disagreements. Every time a serious conflict is resolved constructively, the relationship becomes less fragile and more able to withstand crises and problems.

6. Keep the relationship clear of irritations and resentments so positive feelings can be experienced fully. A good conflict may do a lot to resolve the small tensions of interacting with others.

7. Release emotions (such as anger, anxiety, insecurity, and sadness) that, if kept inside, make us mentally sick. A conflict a day keeps depression away!

8. Clarify what you care about, are committed to, and value. You only fight over wants and goals you value. And you fight much more frequently and intensely with people you value and care about. The more committed you are to your goals, and the more committed you are to the other person, the more frequent and intense are the conflicts.

9. Add fun, enjoyment, excitement, and variety to your life. Being in a conflict reduces boredom, gives you new goals, motivates you to take action, and stimulates interest. Life would be incredibly boring in the absence of conflict.

Third, what determines whether a conflict is constructive or destructive are the procedures taken to manage the conflict. To manage conflicts with skill, finesse, and grace, you need:

1. To understand the procedures for managing conflicts constructively. Further, everyone involved must understand and use the same procedures. Different individuals often have quite different ideas about how to manage conflicts. Some rely on physical dominance through threats and violence. Others use verbal attack, the cold shoulder, giving in, or getting even. When two individuals involved in a conflict are using different procedures, chaos results. If conflicts are to be managed constructively, everyone has to use the same procedures to resolve them. Because the procedures for resolving conflicts constructively are not learned in most families or from television, movies, or novels, students must learn them at school.

2. The opportunity to practice, practice, practice the procedures to gain real skill and expertise in their use. Resolving conflicts takes great skill and considerable practice. Schools need to emphasize overlearning of the conflict resolution procedures by having students practice the procedures again and again.

3. Norms and values to encourage and support use of the procedures. Just because people know how to manage 
conflicts constructively does not mean that they will do so. As long as school norms emphasize working alone and valuing "winners," students will "go for the win" in a conflict rather than by trying to solve the problem.

Based on these points (conflicts are inevitable, a sign of commitment, and potentially constructive), schools are advised to welcome and face conflicts rather than to avoid and repress conflicts. To do so, students need to learn how to be peacemakers.

\section{TEACHING STUDENTS TO BE PEACEMAKERS PROGRAM}

We began the Teaching Students to Be Peacemakers Program in the 1960s. It originated from:

1. Our research on integrative negotiations (Johnson, 1967), perspective taking in conflict situations (Johnson, 1967, 1971a), conflict resolution in the school (Johnson, 1970, 1971b; Johnson, Johnson, \& Johnson, 1976), communication in conflict situations (Johnson, 1974), and constructive conflict (Johnson, 1970; Johnson \& Johnson, 1979).

2. Our development of social interdependence theory (Deutsch, 1949; Lewin, 1951; Johnson, 1970; Johnson \& Johnson, 1989; Watson \& Johnson, 1972).

3. Our training of elementary, junior-high, high-school and college students and adults in how to manage conflicts constructively (Johnson, 1970, 1972/1993, 1978/ 1991, 1983; Johnson \& Johnson, 1975/1994a). Besides regular students, teachers, and administrators, we taught delinquents, runaways, drug-abusers, and married couples in therapy how to manage their conflicts more constructively.

The Teaching Students to Be Peacemakers Program is a 12-year spiral program in which students learn increasingly sophisticated negotiation and mediation procedures (Johnson \& Johnson, 1995b, 1995c). It focuses on teaching all students in a school to be peacemakers. We have implemented the peacemaker program in schools throughout North America, Europe, and several countries in Asia, Central and South America, the Middle East, and Africa.

The Teaching Students to Be Peacemakers Program has six steps.

1. Create a cooperative context. Considerable evidence and practical experience demonstrate that when individuals are in competition, they will strive for a "win" in conflicts and not try to solve the problem. A problem- solving approach requires the disputants to recognize their long-term interdependence and the need to maintain effective working relationships with each otherconditions that exist only in a cooperative context.

2. Teach students to recognize when a conflict is and is not occurring. Many students see conflicts as always involving anger, hostility, and violence and do not recognize conflicts as such when they lead to laughter, insight, learning, and problem solving.

3. Teach students a concrete and specific procedure for negotiating agreements. Everyone involved can thus achieve their goals while maintaining or even improving the quality of their relationship. Telling students to "be nice" or "talk it out," or "solve your problem" is not enough.

4. Teach students to use a concrete and specific mediation procedure. Give them enough practice in using this procedure to develop some expertise. If students are to mediate their schoolmates' conflicts, they must know how to do so. This initial training of the nature of conflict and how to negotiate and mediate usually consists of approximately 30 half-hour lessons.

5. Implement the peer mediation program. Working in pairs, at first, mediators are made available to help schoolmates negotiate more effectively. The mediator's role is rotated so each student is a mediator.

6. Continue the training in negotiation and mediation procedures weekly throughout first through twelfth grades to refine and upgrade students' skills. To become competent in resolving conflicts takes years and years. Any thought that a few hours of training is enough to ensure constructive conflict management is terribly misguided.

Each of these steps will be discussed in more detail in the following pages.

\section{Creating a Cooperative Context}

In beginning a conflict resolution and peer mediation program, we have to focus on the total school environment and create an awareness of students' interdependence and interaction. A conflict resolution program should seek to do more than change individual behavior. Instead, it should transform the total school environment into a learning community in which students live by a credo of nonviolence and problem solving. In addition, students need to recognize that they manage conflicts in long-term, ongoing relationships in a different way than they do in ad hoc, one-time, temporary relationships. In ongoing, long-term relationships, the future of the relationship has to be taken into account along with the 
interests of each disputant. Schools involve long-term, ongoing, interdependent relationships and, therefore, conflicts should be managed accordingly.

If conflicts are to be managed constructively, they must occur in a cooperative, not a competitive, context. Attempting to teach students to manage conflicts constructively makes little sense if the school is structured so students are pitted against each other in competition for scarce rewards (such as teacher attention and grades of " $\mathrm{A}$ ") and students have to defeat each other to get what they want. In competition, rewards are restricted to the few who perform the best (Johnson \& Johnson, 1989). Competitors typically have a short-term time orientation and focus all their energies on winning with little or no paid to the long-term interest in maintaining good relationships. Competitors tend to avoid communicating with each other, misperceive each other's position and motivations, be suspicious of each other, deny the legitimacy of others' needs and feelings, and see the situation only from their own perspective.

For conflicts to be resolved constructively, a cooperative context must be established. A cooperative context entails setting mutual goals that all participants are committed to achieving (Deutsch, 1973; Johnson \& Johnson, 1989). Cooperators tend to seek outcomes that are beneficial to everyone involved. Cooperators typically have a long-term time orientation and focus their energies both on achieving goals and on maintaining good working relationships with others. Communication is apt to be frequent, complete, and accurate, with each person interested in informing the other as well as being informed. Cooperators are more likely to perceive other participants' positions and motivations accurately. Because they tend to trust and like each other, they usually are willing to respond helpfully to each other's wants, needs, and requests. Cooperators tend to recognize the legitimacy of each other's interests and search for a solution that accommodates the needs of both sides. Conflicts are more likely to be defined as mutual problems to be solved in ways that benefit everyone involved.

A cooperative context is established most easily by structuring the majority of learning situations cooperatively (Johnson \& Johnson, 1989; Johnson, Johnson, \& Holubec, 1993). Students should spend most of the day working together in cooperative learning groups so their ongoing interdependence and need for future interaction are clear. Hundreds of studies indicate that cooperative learning, compared to competitive and individualistic learning, tends to promote greater effort to achieve (which includes retention, higher-level reasoning, process gain, intrinsic motivation, achievement motivation, transfer), more positive relationships among students (including students who are heterogeneous in terms of ethnicity, gender, culture, and achievement as well as academic and per- sonal social support), and greater psychological adjustment (encompassing psychological health, self-esteem, and social competence) (Johnson \& Johnson, 1989). Because cooperative learning has considerable benefits, most teachers should welcome the opportunity to create a cooperative context that will enhance the success of conflict resolution programs.

When conflict resolution and peer mediation programs are implemented in the existing competitive/individualistic context of schools, their effectiveness can be compromised severely (Johnson \& Johnson, 1975/1994b, 1995c). When the context and the procedures used to manage the conflict are congruent (an integrative procedure used in a cooperative context or a distributive procedure used in a competitive context), conflicts tend to be managed constructively. When the context and the conflict resolution procedures are incongruent (an integrative procedure used in a competitive context or a distributive procedure used in a cooperative context), destructive outcomes tend to result. To teach students how to seek solutions to problems rather than to strive for a "win," educators must create a cooperative context in the classroom and school.

Once a cooperative context has been established, students may be taught directly to recognize conflicts when they occur. Then they are able to learn the procedures and skills required to manage conflicts constructively.

\section{Teaching Students What Is and Is Not a Conflict}

Most of the diverse conflict resolution programs in schools are either cadre or total student body programs. In the cadre approach, a few students are trained to serve as peer mediators for the entire school. In the total student body approach, every student learns how to manage conflicts constructively by negotiating agreements and mediating schoolmates' conflicts. The responsibility for peer mediation is rotated throughout the entire student body (or class) so every student gains experience as a mediator. The greater number of students trained in how to negotiate and mediate, the greater is the number of conflicts that may be managed constructively in the school.

Whether training a cadre or an entire class or student body, teaching students what is and is not a conflict is an important early step in conflict management training. Students generally have a negativity bias, in which they tend to view conflicts as involving anger and violence and, therefore, tend to overestimate the frequency of conflicts involving anger and violence and underestimate the incidents of actual conflicts. The most common types of conflicts in schools are verbal harassments (name-calling, insults), verbal arguments, rumors and gossip, physical fights, and dating/relationship issues. Although physical and verbal aggression may be more frequent 
in urban than in suburban schools, it almost never involves serious altercations or violations of law. The first part of the Teaching Students to be Peacemakers Program, therefore, is to teach students what is and is not a conflict so they can become aware of (a) how they manage their conflicts and (b) how to manage conflicts constructively. Once students understand what is and is not a conflict, they are taught how to negotiate constructive resolutions to conflicts and how to mediate the conflicts of their peers.

\section{Teaching Students to Negotiate}

The best way I know how to defeat an enemy is to make him a friend.

(Abraham Lincoln)

The heart of conflict resolution training is teaching students how to negotiate constructive resolutions to their conflicts. All students in all schools need to learn how to negotiate (and mediate). Negotiation is a process by which people try to work out a settlement when they (a) have both shared and opposing interests and (b) want to come to an agreement (Johnson \& Johnson, 1994). The two types of negotiations are distributive or "win-lose" (in which one person benefits only if the opponent agrees to make a concession) and integrative or problem solving (in which disputants work together to create an agreement that benefits everyone involved). Only in very limited conflicts involving ad hoc, one-time relationships are win-lose negotiations appropriate. In ongoing relationships that have a future as well as a present, an integrative approach to negotiations is the only constructive alternative. The steps in using problem solving negotiations are (Johnson \& Johnson, 1995b, 1995c):

1. Describing what you want. "I want to use the book now." This means using good communication skills and defining the conflict as a small and specific mutual problem.

2. Describing how you feel. "I'm frustrated." Disputants must understand how they feel and communicate it openly and clearly.

3. Describing the reasons for your wants and feelings. "You have been using the book for the past hour. If I don't get to use the book soon, my report won't be done on time. It's frustrating to have to wait so long." This includes expressing cooperative intentions, listening carefully, separating interests from positions, and differentiating before trying to integrate the two sets of interests.

4. Taking the other's perspective and summarizing your understanding of what the other person wants, how the other person feels, and the reasons underlying both.
"My understanding of you is ..." This includes understanding the perspective of the opposing disputant and being able to see the problem from both perspectives simultaneously.

5. Inventing three optional plans that maximize joint benefits. "Plan A is ..., Plan B is ..., Plan C is ..." This requires inventing creative options to solve the problem.

6. Choosing one plan and formalizing the agreement with a hand shake. "Let's agree on Plan B!" A wise agreement is fair to all disputants and is based on principles. It maximizes joint benefits and strengthens disputants' ability to work together cooperatively and resolve conflicts constructively in the future. It specifies how each disputant should act in the future and how the agreement will be reviewed and renegotiated if it does not work.

Students need to practice this procedure again and again until it becomes an automatic habit. If students have to stop and think what they should do, it may be too late to manage the conflicts constructively. Overlearning the integrative negotiation procedure is needed so it is available for use in conflicts with intense emotions such as fear and anger. Students need to overlearn the negotiation procedure and become skillful in its use in relatively easy situations before they can be expected to use it to resolve emotionally charged conflicts. Mediation, furthermore, is easier and more effective when all students are skilled in integrative negotiating procedures.

\section{Teaching Students to Mediate Schoolmates' Conflicts}

$$
\text { A soft answer turneth away wrath. (Bible) }
$$

When students cannot negotiate a constructive resolution to their conflicts successfully, peer mediators should be available. In the Teaching Students to Be Peacemakers Program, all students are taught the procedures and skills they need to mediate their classmates' conflicts of interests (Johnson \& Johnson, 1995c). A mediator is a neutral person who helps two or more people resolve their conflict, usually by negotiating an integrative agreement. The mediator has no formal power over either disputant. A mediator does not tell disputants what to do or decide who is right and who is wrong. When you mediate, you stand in the middle and help disputants go through each step of problem-solving negotiations so they reach an agreement that is fair, just, and workable.

Mediation usually is contrasted with arbitration. Arbitration is the submission of a dispute to a disinterested third party (such as a teacher or a principal) who makes a final and binding judgment as to how the conflict will be resolved. Mediation consists of four steps (Johnson \& Johnson, 1995c): 
1. End hostilities. The mediator ensures that disputants end hostilities and disputants cool off. Usually the disputants ask the mediator for help. In some cases the mediator may see a dispute taking place and ask if he or she can be of service. In rare instances the mediator may have to get a teacher or an administrator to break up a fight. The mediator must be sure that all disputants are emotionally capable of problem solving and conflict resolution. If disputants are too angry to problem solve, they must cool down before mediation begins.

2. Ensure that disputants are committed to the mediation process. The mediator introduces the process of mediation and sets the ground rules to ensure that disputants are committed to the mediation process and ready to negotiate in good faith. The mediator first introduces him- or herself. The mediator then asks the disputants if they want to solve the problem and does not proceed until both answer "yes." Then the mediator explains:

- "Mediation is voluntary. My role is to help you find a solution to your conflict that is acceptable to both of you."

- "I'm neutral. I won't take sides or attempt to decide who is right or wrong. I'll help you decide how to solve the conflict."

- "Each person will have the chance to state his or her view of the conflict without interruption."

- "The rules you must agree to are (1) agree to solve the problem, (2) no name calling, (3) do not interrupt, (4) be as honest as you can, (5) if you agree to a solution, you must abide by it (you must do what you have agreed to do), and (6) anything said in mediation is confidential (you, the mediator, will not tell anyone what is said)."

3. Help disputants negotiate successfully with each other. The mediator carefully takes the disputants through the negotiation procedure by helping disputants:

- Define the conflict by having disputants jointly define the conflict by asking each disputant, "What happened, what do you want, how do you feel?" The mediator paraphrases what each disputant says when necessary to demonstrate that the mediator is listening to and understanding what the disputants are saying and when the mediator believes the other disputant does not understand clearly what the other person is saying. The mediator also enlarges the shadow of the future by highlighting the ways the disputants will have to work cooperatively with each other in the future.

- Exchange reasons for their positions by helping the disputants present their reasons and the rationale for their positions and understand the differences between their positions. The mediator keeps disputants focused on the issue, not on peripheral issues such as their anger toward each other, equalizes power between the disputants, recognizes disputants' constructive behaviors during negotiations, and reframes the issue by helping disputants change their perspectives.

- Reverse perspectives so that each person is able to present the other's position and feelings to the other's satisfaction. The mediator also may role play the conflict and switch roles at critical points.

- Invent at least three options that maximize joint outcomes and leave disputants feeling they have benefited. The mediator encourages creative thinking.

4. Formalize the agreement. Reach a wise agreement and shake hands to formalize it. The mediator helps disputants weigh the advantages and disadvantages of each alternative and select the one they wish to implement. The disputants sign a Mediation Report Form to formalize their commitment to implement the agreement and abide by its conditions. The mediator becomes the keeper of the contract and checks back with the disputants a day or so later to see if the agreement is working.

Table 1 summarizes the steps in mediation and offers possible mediator statements.

TABLE 1

Steps to Mediation

\begin{tabular}{|l|l|}
\hline Steps & Possible Statements \\
\hline End hostilities & "Would you like a mediator?" \\
\hline Ensure commitment to mediation & "You must follow four rules." \\
\hline Facilitate negotiations & "How do you feel?" \\
\hline Formalize the agreement & $\begin{array}{l}\text { "Are you willing to sign the } \\
\text { agreement?" }\end{array}$ \\
\hline
\end{tabular}

If mediation by peers fails, the teacher mediates the conflict. If teacher mediation fails, the teacher arbitrates by deciding who is right and who is wrong. If that fails, the principal mediates the conflict. If that fails, the principal arbitrates. Teaching all students negotiation and mediation procedures and skills and implementing a peer mediation program results in a schoolwide discipline program that empowers students to regulate and control their own and their classmates' actions. Teachers and administrators are then freed to spend more of their energies on instruction. 


\section{Implementing the Peacemaker Program}

If civilization is to survive, we must cultivate the science of human relationships-the ability of all peoples, of all kinds, to live together, in the same world, at peace.

(Franklin Delano Roosevelt)

Once students understand how to negotiate and mediate, the teacher implements the Peacemaker program. Each day the teacher selects two class members to serve as official mediators. Any conflicts that students cannot resolve themselves are referred to the mediators. The mediators wear official Tshirts, patrol the playground and lunchroom, and are available to mediate any conflicts that arise in the classroom or school. The role of mediator is rotated so all students in the class or school serve as mediators an equal amount of time. At first students mediate in pairs. This ensures that shy and nonverbal students get the same amount of experience as more extroverted and verbally fluent students. Mediating classmates' conflicts is perhaps the most effective way of teaching students the need for the skillful use of each step in the negotiation procedure.

The processes of negotiation and mediation allow students to practice joint decision making within a structure that emphasizes a solution/settlement acceptable to all parties involved and, therefore, is fair. Students are given the power to decide the outcome (within the constraints of school policy and the law) and solve a joint problem. For a settlement to be reached, they take responsibility for their conflict. Negotiation and mediation are self-empowering. These procedures enable students to make decisions about issues and conflicts that affect their own lives rather than have a decision imposed on them by teachers and administrators.

\section{Continuing Lessons to Refine and Upgrade Students' Skills}

Booster sessions are needed throughout the year to maintain the use of the negotiation and mediation procedures. Gaining real expertise in resolving conflicts constructively takes years and years of training and practice. It may even take a whole lifetime. A few hours of training clearly is not sufficient to teach students how to negotiate or mediate skillfully. The initial Peacemaker training is not enough to create highly skilled negotiators and mediators. At least twice a week or so, students should receive further training or practice in negotiating and mediating. The Teaching Students to Be Peacemakers Program is intended to be a 12 -year spiral program that is retaught each year at a more sophisticated and complex level.

One of the most natural ways to integrate negotiation and mediation training into the fabric of school life is to integrate it into academic lessons. Literature, history, and science involve conflict. Almost any lesson in these subject areas can be modified to include role-playing situations in which the negotiation or mediation procedures are used. In our recent research, for example, we have integrated the Peacemaker training into English literature units involving a novel. Each of the major conflicts in the novel was used to teach the negotiation or mediation procedures, and all students role played how to use the procedures to resolve the conflicts in the novel constructively. With some training, teachers can integrate the Peacemaker program readily into academic units.

\section{RESEARCH ON PEACEMAKER PROGRAM}

We have conducted more than 10 studies on the effectiveness of the Teaching Students to Be Peacemakers Program (Johnson \& Johnson, 1995d; Johnson, Johnson, \& Stevahn, 1995). The studies focused on peer mediation programs in elementary, middle school, and high school settings. The programs were evaluated over a period of several months to a year. The schools were in urban and suburban school districts. Students varied from lower to upper middle class socioeconomically and were from diverse ethnic and cultural backgrounds. Mediators were drawn from a wide variety of ethnic backgrounds. The studies were carefully controlled field-experimental studies with high internal and external validity. The research addressed the following series of questions:

- How often do conflicts among students occur, and what are the most commonly occurring conflicts? The findings indicate that students engage in conflicts daily. In the suburban schools studied, most of the conflicts reported centered on the possession and access to resources, preferences about what to do, playground issues, and turn-taking. Some conflicts involved physical and verbal aggression. In the urban elementary school studied, the vast majority of conflicts referred to mediation involved physical and verbal violence.

- Before training, what strategies did students use to manage their conflicts? Before training, students generally managed their conflicts through trying to win by (a) forcing the other to concede (either by overpowering the other disputant or by asking the teacher to force the other to give in) or (b) withdrawing from the conflict and the other person. One of the teachers stated in her $\log$, "Before training, students viewed conflict as fights that always resulted in a winner and a loser. To avoid such an unpleasant situation, they usually placed the responsibility for resolving conflicts on me, the teacher." Students seem to lack all knowledge of how to engage in problem-solving, integrative negotiations. 
- Was the Peacemaker training successful in teaching students the negotiation and mediation procedures? After the Peacemaker training, the students knew the negotiation and mediation procedures and retained their knowledge up to 7 months after the training ended.

- Could students apply the negotiation and mediation procedures to conflicts? For all three types of measures used, students were able to apply the negotiation and mediation procedures to a variety of conflicts.

- Do students transfer the negotiation and mediation procedures to nonclassroom and nonschool situations? Our studies demonstrated that students did in fact use the negotiation and mediation procedures in the hallways, lunchroom, and playground. In addition, students used the procedures in family settings.

-When given the option, would students engage in "winlose" or problem-solving negotiations? Following the Peacemaker training, students were placed in a negotiation situation in which they could either try to win or maximize joint outcomes. Untrained students almost always strive to win. Most trained students, on the other hand, focused on maximizing joint outcomes.

- Does the Peacemaker training increase students' academic achievement? In three of our studies, we integrated the Peacemaker training into English literature units. While studying a novel, students also learned the negotiation and mediation procedures and used them to understand the dynamics among the major characters. The students were given an achievement test following the end of the unit and again several months later. The results indicated that the students who received the integrated training achieved significantly higher on the achievement and retention tests than did students who spent all their time studying the novel without learning the conflict resolution procedures.

- Does the Peacemaker training result in fewer discipline problems that have to be managed by the teacher and the administration? In our studies the number of discipline problems the teacher had to deal with decreased by about 60 percent, and referrals to the principal dropped about 95 percent.

- Does the Peacemaker training result in more positive attitudes toward conflict? Untrained students uniformly had negative attitudes toward conflicts. After training, students had more positive attitudes toward conflict. Teachers and administrators and parents perceived the peacemaker program to be constructive and helpful. Many parents whose children were not part of the project requested that their children receive the training next year, and a number of parents requested that they receive the training themselves so they could use the procedures to improve conflict management within the family.

Overall, these findings provide considerable empirical validation of the effectiveness of the Peacemaker program and of conflict resolution and peer mediation training in general.

\section{SCHOOL DISCIPLINE PROGRAM}

Classroom and school discipline programs may be classified on a dimension from a basis in giving external rewards and punishments that control and manage student behavior to a basis in teaching students the competencies and skills required to resolve their interpersonal conflicts constructively, cope with stress and adversity, and behave in appropriate and constructive ways. At one end of the continuum, the focus is on the faculty and staff controlling and managing student behavior. At the other end of the continuum, the focus is on students regulating their own and their peers' actions.

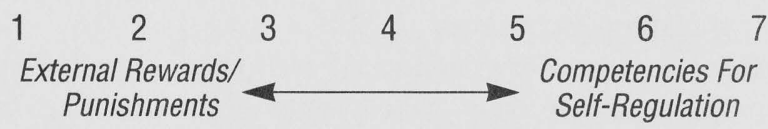

Most discipline programs are clustered at end of the continuum in which adults administer external rewards and punishment. Thus, the faculty has to monitor student behavior, determine whether it is or is not within the bounds of acceptability, and force students to terminate inappropriate actions. When the infractions are minor, the staff often arbitrates ("The pencil belongs to Mary; Jane be quiet and sit down") or cajoles students to end hostilities ("Let's forgive and forget"; "Shake hands and be friends"). If that does not work, students may be sent to the principal's office for a stern but cursory lecture about the value of getting along, a threat that if the conflict continues, more drastic action will ensue, and a final admonition to "Go and fight no more." If that does not work, time-out rooms may be used. Eventually, some students are suspended or expelled from school. Such programs teach students that adults or authority figures are needed to resolve conflicts. These programs cost a great deal in instructional and administrative time and work only as long as students are under surveillance. Students are not empowered. Adults may become more skillful in how to control students, but students do not learn the procedures, skills, and attitudes required to resolve conflicts constructively in their personal lives at home, in school, at work, and in the community.

At the other end of the continuum are programs aimed at teaching students self-responsibility and self-regulation. Selfregulation is the ability to act in socially approved ways in the absence of external monitors. It is the ability to initiate and 
cease activities according to situational demands. Self-regulation is a central and significant hallmark of cognitive and social development. To regulate their behavior, students must monitor their own behavior, assess situations and take other people's perspectives to make judgments as to which behaviors are appropriate, and master the procedures and skills required to engage in the desired behavior. In interaction with other people, students have to monitor, modify, refine, and change how they behave in order to act appropriately and competently.

If students are to learn how to regulate their behavior they must have opportunities to (a) make decisions regarding how to behave, and (b) follow through on the decisions made. Allowing students to be joint architects in matters affecting them promotes feelings of control and autonomy. Then teachers and administrators can concentrate on instruction rather than control.

\section{STRUCTURING ACADEMIC CONTROVERSIES}

In addition to implementing the Teaching Students to Be Peacemakers Program, faculty may use intellectual, academic conflicts as an inherent part of the instructional program to increase student achievement, higher-level reasoning, motivation to learn, and conflict skills (Johnson \& Johnson, 1995a). Academic controversy exists when one student's ideas, information, conclusions, theories, and opinions are incompatible with those of another student, and the two seek to reach an agreement. Over the past 25 years, we (with colleagues such as Dean Tjosvold and Karl Smith) have developed a theory of controversy, tested it by conducting more than 20 experimental and field-experimental studies, developed a series of curriculum units on energy and environmental issues structured for academic controversies, and trained teachers to use academic controversies in schools and colleges throughout the United States, Canada, and a number of other countries (Johnson \& Johnson, 1979, 1989, 1995a).

Structuring academic controversy into learning situations results in students learning that conflicts are potentially constructive and even enjoyable. The procedure for structuring academic controversies is to have students follow these steps:

1. Prepare scholarly positions on an academic issue.

2. Advocate these positions.

3. Refute the opposing positions while rebutting criticisms of their position.

4. View the issue from both perspectives.

5. Come to a consensus about their "best reasoned judgment" based on a synthesis of the two positions.

Participating in academic controversies teaches students how to (a) prepare, present, and defend a position, (b) take an opposing perspective, (c) make creative, high-quality decisions that integrate the best information and reasoning from both sides, and (d) engage in a set of social skills such as "criticizing ideas without criticizing people." Similar to cooperative learning, the use of academic controversy may be welcomed by educators because it results in improved student achievement, critical thinking, higher-level reasoning, intrinsic motivation to learn, and a number of other important educational outcomes (Johnson \& Johnson, 1979, 1989, 1995a).

Engaging in academic controversies demonstrates the value of conflict and promotes positive attitudes toward engaging in conflict. The skills learned in controversy support and reinforce the skills used in negotiation and mediation. A detailed program to train teachers in how to structure academic controversies to ensure that all students are intellectually challenged within the classroom is presented in Creative Controversy: Intellectual Challenge in the Classroom (Johnson \& Johnson, 1995c).

\section{CREATING A CONFLICT-POSITIVE SCHOOL}

Schools do not become orderly and peaceful places in which high-quality education can take place by suppressing the occurrence of conflicts among students. For a variety of reasons, many students want to engage in conflicts. In interviewing inner-city, seventh grade, lower-class, minority students in New York City, Opotow (1991) found that the students perceived fights as being more constructive than destructive.

The students viewed fights as necessary and desirable to maintain valued social norms, deter harmful behavior, provide protection from victimization, provide gains in status, increase self-awareness, clarify personal identity, clarify others' identities, clarify dominance hierarchies, initiate friendships, and provide enjoyable and entertaining experiences. The students reported that in conflicts they found opportunities for (a) modifying the status quo and the behavior of troublesome peers, (b) increasing self-protection, social advancement, personal worth, interpersonal insight, conflict resolution, and excitement, (c) providing heroic drama that generated an oral history of danger, heroism, and good versus evil, and (d) providing moral discourse and clarification of values and codes of behavior. Opotow concluded that these inner-city seventh graders were fascinated clearly by and drawn to conflicts. They liked to start conflicts, watch them, hear about them, and discuss them. Telling students not to fight obviously is not an effective strategy to pursue.

Schools are much better advised to seek an orderly and safe learning environment by encouraging conflicts and their constructive management. A conflict-positive school is one where conflicts are encouraged and managed constructively to maxi- 
mize their potential in enhancing the quality of teaching, learning, and school life in general (Johnson \& Johnson, 1995c). Conflicts are not the problem; they are part of the solution and should be a pervasive part of school life. Conflicts not only are inevitable, but also, when they are managed constructively, they are healthy and valuable and revitalize and rejuvenate the school. Conflicts can be constructive and valuable.

To summarize:

- Conflicts can increase achievement and long-term retention of academic material.

- Conflicts are the key to using higher-level cognitive and moral reasoning and healthy cognitive, social, and psychological development.

- Conflicts focus attention on problems that have to be solved and energize us to solve them.

- Conflicts clarify who you are, what your values are, what you care about and are committed to, and how you may need to change.

- Conflicts help you understand who the other person is and what his or her values are.

- Conflicts strengthen relationships by increasing your confidence that the two of you can resolve your disagreements and by keeping the relationship clear of irritations and resentments so that positive feelings can be experienced fully.

- Conflicts can release anger, anxiety, insecurity, and sadness that, if kept inside, makes us mentally sick.

- Conflicts can be fun.

What determines whether conflicts result in these positive outcomes is how skillfully students (and faculty) use the integrative negotiation and mediation procedures.

\section{A LIFE-LONG ADVANTAGE}

A number of recent research studies have found that executives in high-level positions spend much of their time dealing with conflicts. The more skillful they are at doing so, the more successful their careers. Because conflicts occur continually, and because so many people are so unskilled in managing conflicts, teaching students how to resolve conflicts constructively is one of the best investments schools can make.

Once learned, conflict skills go with students to every situation and every relationship. Students do not have to manage every conflict constructively, but the ability to do so should be in their repertoire. Knowing how to resolve conflicts with skill and grace will give students a developmental advantage and increase their future academic and career success, improve the quality of relationships with friends, colleagues, and family, and generally enhance their lifelong happiness.

\section{SUMMARY AND CONCLUSIONS}

The frequency of conflicts is not the problem facing schools. In many cases schools are too conflict-avoidant and need to increase the frequency with which conflicts occur among students and between students and faculty. Conflict has many positive outcomes that cannot occur unless conflict is encouraged. The problem facing schools is how to manage conflicts in constructive and healthy ways. The major barrier to solving this problem is students' lack of effective skills in conflict resolution. Students do use procedures for managing conflicts, but often these procedures are not constructive and not shared by all classmates. The many different methods of managing conflicts within classrooms create some chaos in how conflicts are managed. This is especially true when students are from different cultural, ethnic, social class, and language backgrounds. Life in schools gets easier when all students (and staff members) use the same set of negotiation and mediation procedures in managing conflicts.

When students are taught how to negotiate and are given opportunities to mediate their classmates' conflicts, they are given the tools to (a) regulate their behavior through selfmonitoring, (b) judge what is appropriate given the situation and the perspective of the other person, and (c) modify how they behave accordingly. Students then have the opportunity to resolve their dispute themselves, in mutually satisfactory ways, without having to engage a teacher's attention. This empowers the students and reduces the demands on teachers and administrators, who then are able to devote less time to establishing and maintaining control over students and spend more time on instruction.

Teaching all students negotiation and mediation procedures and skills and implementing a peer mediation program results in a schoolwide discipline program focused on empowering students to regulate and control their own and their classmates' actions. When a conflict occurs, the students involved first try to negotiate a resolution. If that fails, a classmate mediates their conflict. If that fails, the teacher attempts to mediate the conflict. If that fails, the teacher arbitrates by deciding who is right and who is wrong. If that fails, the principal mediates the conflict. If that fails, the principal arbitrates.

Every student needs to learn how to manage conflicts constructively. Without training, many students may never learn how to do so. Teaching every student how to negotiate and mediate will ensure that future generations are prepared to manage conflicts constructively in career, family, community, national, and international settings. The process is neither easy nor quick. Reducing smoking in America took more 
than 30 years. Reducing drunk driving took more than 20 years. Ensuring that children and adolescents can manage conflicts constructively may take even longer. The more years students spend learning and practicing negotiation and mediation procedures, the more likely they will be to actually use the procedures skillfully both in the classroom and beyond the school door.

\section{REFERENCES}

Deutsch, M. (1949). A theory of cooperation and competition. Human Relations, 2, 129-152.

Deutsch, M. (1973). The resolution of conflict. New Haven, CT: Yale University Press.

Elam, S., Rose, L., \& Gallup, A. (1994, September). The 26th annual Gallup poll of the public's attitudes toward the public schools. Phi Delta Kappan, 76, 41-56.

Johnson, D. W. (1967). The use of role reversal in intergroup competition. Journal of Personality \& Social Psychology, 7, 135-141.

Johnson, D. W. (1970). Social psychology of education. Edina, MN: Interaction Book Co.

Johnson, D. W. (1971a). Role reversal: A summary and review of the research. International Journal of Group Tensions, 1, 318-334.

Johnson, D. W. (1971b). Students against the school establishment: Crisis intervention in school conflicts and organizational change. Journal of School Psychology, 9, 84-92.

Johnson, D. W. (1974). Communication and the inducement of cooperative behavior in conflicts: A critical review. Speech Monographs, 41, 64-78.

Johnson, D. W. (1983). Resolving marital conflicts constructively. Edina, MN: Interaction Book Co.

Johnson, D. W. (1972/1993). Reaching out: Interpersonal effectiveness and self-actualization (5th ed.). Englewood Cliffs, NJ: Prentice-Hall.
Johnson D. W., \& Johnson, F. (1975/1994a). Joining together: Group theory and group skills (5th ed.). Englewood Cliffs, NJ: Prentice-Hall.

Johnson, D. W., \& Johnson, R. (1975/1994b). Learning together and alone. Englewood Cliffs, NJ: Prentice Hall.

Johnson, D. W., \& Johnson, R. (1979). Conflict in the classroom: Controversy and learning. Review of Educational Research, $49,51-61$.

Johnson, D. W., \& Johnson, R. (1987). Creative conflict. Edina, MN: Interaction Book Co.

Johnson, D. W., \& Johnson, R. (1989). Cooperation and competition: Theory and research. Edina, MN: Interaction Book Co.

Johnson, D. W., \& Johnson, R. (1995a). Creative controversy: Intellectual challenge in the classrocm. Edina, MN: Interaction Book Co.

Johnson, D. W., \& Johnson, R. (1995b). My mediation notebook (3d ed.). Edina, MN: Interaction Book Co.

Johnson, D. W., \& Johnson, R. (1995c). Teaching students to be peacemakers. Edina, MN: Interaction Book Co.

Johnson, D. W., \& Johnson, R. (1995d). Teaching students to be peacemakers: Results of five years of research. Peace and Conflict: Journal of Peace Psychology.

Johnson, D. W., Johnson, R., \& Holubec, E. (1993). Circles of learning. Edina, MN: Interaction Book Co.

Johnson, D. W., Johnson, R., \& Johnson, F. (1976). Promoting constructive conflict in the classroom. Notre Dame Journal of Education, 7, 163-168.

Johnson, D. W., Johnson, R., \& Stevahn, L. (1995). Three new studies on conflict resolution/peer mediation training. Paper presented at annual meeting of National Association for Mediation Education (NAME), Seattle.

Lewin, K. (1951). Field theory in social science. New York: Harper. Opotow, S. (1991). Adolescent peer conflicts. Education and Urban Society, 23(4), 416-441.

Watson, G., \& Johnson, D. W. (1972). Social psychology: Issues and insights (2nd ed.). Philadelphia: Lippincott. 


\section{Professional update}

\author{
Council for Exceptional Children \\ Annual Convention
}

April 1-5, 1996

Orange County Convention Center

Orlando, Florida

Contact: Council for Exceptional Children 1920 Association Drive

Reston, Virginia 22091

\section{Association for Education and Rehabilitation of the Blind and Visually Impaired}

July 20-24, 1996

Adam's Mark Hotel

St. Louis, Missouri

Contact: Association for Education and Rehabilitation of the Blind and Visually Impaired 206 North Washington Street Suite 320

Alexandria, Virginia 22314

\section{American Association on Mental Retardation}

May 28-June 1, 1996

San Antonio Marriott Rivercenter Hotel

San Antonio, Texas

Contact: AAMR

444 North Capitol Street, N.W.

Suite 846

Washington, D.C. 20001

\section{NEW BOOK}

\section{A History of Childhood and Disability \\ by Philip L. Safford and Elizabeth J. Safford}

This book is a significant intellectual contribution to all special education and disability literature. The authors present a sobering glance at a world in which family selfreliance once meant neglect, abuse, and death for children with disabilities. Comprehensive and inclusive of an impressive array of primary and secondary sources, it presents an interdisciplinary portrayal of children considered exceptional and how services have evolved through time in response to their diverse needs.

With a broad beginning covering the significance of childhood disability from the time of Aristotle to the present, the book has a chronological base, with subsequent chapters delving into the specific conditions traditionally associated with specialized approaches and the evolution of treatment. Closing with a modern perspective and a synthesis of themes, we are reminded that the "new history" of exceptional children is still emerging and yet to be written. This book is available from Teachers College Press, Columbia University, New York, NY 10027. 